\title{
A TWO-PRODUCT INVENTORY SYSTEM WITH PRODUCT INTERACTION
}

\author{
V.S.S. Yadavalli and C. Hargreaves* \\ Department of Industrial and Systems Engineering \\ University of Pretoria \\ yadavalli@postino.up.ac.za \\ *University of Durban-Westville
}

\begin{abstract}
In this paper, we study a two-component continuous review inventory system. We assume that demand occurs according to a Poisson process and that a demand can be satisfied only if both the components are available in the inventory. Back-orders are not permitted. We assume that the lead-time distribution of one product is arbitrary and the other is exponential. Identifying the underlying process as a semi-regeneration process we find the stationary distribution of the inventory level, the performance measures such as mean stationary rate of number of lost demands, the demands and the reorders made. A numerical example illustrates the results.
\end{abstract}

\section{OPSOMMING}

Die artikel ondersoek 'n tweekomponent- deurlopende oorsigvoorraadstelsel. Daar word aanvaar dat aanvraag 'n Poissonproses is en dat aanvraag slegs bevredig kan word indien beide die komponente in die voorraad beskikbaar is. Agterstallige bestellings word nie toegelaat nie. Daar word aanvaar dat die lewertydverdeling van die een produk arbitrêr en die ander eksponensieël is. Indien die onderliggende proses as 'n semigenerasieproses geïdentifiseer word, kan die stasionêre verspreiding van die voorraadvlak bepaal word. Maatstawwe van vertoning soos mediaan- stasionêre koers van die hoeveelheid verlore aanvraag, die aanvraag en herbestellings wat gedoen is word bepaal. 'n Numeriese voorbeeld illustreer die resultate.

\footnotetext{
* Mrs Hargreaves was a PhD student at UNISA and this paper is based on her PhD Thesis
} 


\section{INTRODUCTION}

A common phenomenon that occurs in the maintenance of multi-product inventory systems is that of product interaction. The demand for a particular product may not be satisfied, even though the product is available, for the simple reason that another complementary product is unavailable. For instance, every automobile vehicle is supplied with maintenance kits and some essential spare parts when it is sold. The non-availability of the maintenance kit or some of the spares may prevent the sale of the vehicle. Again, similar types of problem occur in multi-product inventory systems where the end-product is an assembly of several components.

Separate inventory systems for each component are maintained and controlled. These types of inventory are abundant. For example, a dispensing chemist stores several chemicals and, upon receiving the prescription, prepares the compound mixture and then dispenses it to the customer. The non-availability of one of the required chemicals may delay the supply process. As another example, a cycle manufacturer needs a wheel rim, hub and spokes to assemble a wheel and again the non-availability of even one component may inhibit the production of cycles.

In these multi-product inventory systems, equal inventories cannot be maintained for the subproducts due to various costs arising from storage, procurement and stock-out, lead-times, holding costs, opportunity costs and replenishment costs which may be different, depending on the nature of the sub-products. This necessitates the adoption of an optimal ordering policy for such an inventory system.

Schmidt and Nahmias (1985) studied a two-product inventory problem where the end-product was assembled from two components. However, the paper was confined to the examination of periodic review systems. Yano (1987) considered a two-part assembly system where the procurement lead-times of both the parts were stochastic. In this paper, the authors determined planned lead-times for procurement and for assembly production so that the total inventory holding costs for parts and the assembled product, and the tardiness costs for the assembled product, were minimized. Kumar (1989) also studied a multi-part assembly system with stochastic lead-times for the parts and determined the re-order points of each part for the total cost to be minimised.

Fujiwara and Sedarage (1997) considered an EOQ-type model for a production system, where a number of parts were acquired to produce a single product and where the lead-times were random. The author's objective was to determine when to order each part and what lot size to produce so that the average total cost per unit time would be minimised. However, attention needs to be focused on the study of multi-product continuous review inventory systems with product interaction.

In this paper, an attempt is made to fill the gap by presenting a model of a multi-product continuous-review inventory system with product interaction. For simplicity, we assume that two sub-products are assembled together to produce an end-product instantaneously for which there are demands from outside. The demands for the end-products occur according to a Poisson process which is a counting process and can be satisfied only if both the products are 
available in the inventory. Back-orders are not permitted. The two sub-products are brought from outside and are replenished according to a $(s, S)$ policy.

\section{SYSTEM DESCRIPTION}

\subsection{Assumptions and notation:}

A two-product continuous-review assembly inventory system with the following assumptions and notations are considered:

1. The maximum inventory level of a product $i$ is $S_{i}, i=1,2$

2. The re-ordering policy for the product $i$ is $\left(s, S_{i}\right)$, where $S_{i}>2 s_{i}, i=1,2$

3. The lead-times of product 1 have an arbitrary distribution with pdf $g(\bullet)$ and that of product 2 has an exponential distribution with parameter $\mu$.

4. The demands for the end-products occur according to a Poisson process with parameter $\lambda$, $\lambda>0$.

5. Backlogging is not permitted.

$R_{i}: \quad$ Event that a re-order is placed for product $i, i=1,2$.

$\ell$ : $\quad$ Event that a demand is lost.

$d$ : $\quad$ Event that a demand is satisfied.

$N_{d}(t)$ : Random variable representing the number of demands satisfied in the interval, $(0, t]$.

$L_{i}(t)$ : The inventory level of the product $i$ at any time $t, t \geq 0 ; i=1,2$.

$Z(t): \quad\left(L_{1}(t), L_{2}(t)\right)$, the vector process representing the state of the system at time $t$.

$E_{0}$ : $\quad$ Event that denotes the initial condition that a reorder is placed for product 1 and the inventory level of product 2 is

$$
\begin{array}{ll}
j_{o} ; j_{0}=1,2, \ldots, s_{2}, \ldots, S_{2} . & \\
P_{i, j}(t)=P\left[Z(t)=(i, j) / E_{0}\right] ; & i=0,1, \ldots, s_{1}, \ldots, S_{1} \\
& j=0,1, \ldots, s_{1}, \ldots, S_{1}
\end{array}
$$

(C): Convolution symbol

$$
\bar{G}(t)=1-G(t)
$$

\section{AUXILIARY FUNCTION}

To derive an expression for the inventory level distribution of the two products, we first consider the behaviour of the one-product inventory system of product 2 as a one-product system. For this, we define the auxiliary function:

$\phi(i, j, k, t)=P\left[L_{2}(t)=j, N_{d}(t)=k / L_{2}(0)=i\right]$

Since the domain of the usage of this function is restricted, we note that the number $k$ of the demands satisfied in the period can be at most $s_{1}$. Using probabilistic arguments, we obtain $\phi(i, j, k, t)$ 
For $k=0$, we have

$\phi(0,0,0, t)=e^{-\mu t}$

$\phi\left(0, S_{2}-s_{2}, 0, t\right)=\mu e^{-\mu t} C e^{-\lambda t}$

$\phi(i, i, 0, t)=e^{-(\lambda+\mu) t} ; \quad 1 \leq i \leq s_{2}$

$\phi\left(i, i+S_{2}-s_{2}, 0, t\right)=\mu e^{-\mu t} C e^{-\lambda t} ; \quad 1 \leq i \leq s_{2}$

$\phi(i, i, 0, t)=e^{-\lambda t} ; \quad s_{2}+1 \leq i \leq S_{2}$

For $1 \leq k \leq i \leq s_{2}$, we have

$\phi(i, i-k, k, t)=\frac{e^{-(\lambda+\mu) t}(\lambda t)^{k}}{k !} ; \quad k=0,1,2, \ldots$

$\phi\left(i, i-k+S_{2}-s_{2}, k, t\right)=\left[1-e^{-\mu t}\right] e^{-\lambda t} \frac{(\lambda t)^{k}}{k !}$

For $1 \leq k \leq i-s_{2}-1$, we have

$\phi(i, i-k, k, t)=\frac{e^{-\lambda t}(\lambda t)^{k}}{k !} ; \quad s_{2}<i \leq S_{2}$

$\phi(i, i-k, k, t)=\frac{e^{-(\lambda+\mu) t}(\lambda t)^{k}}{k !} ; \quad k=0,1,2$,

For $i-s_{2} \leq k \leq i$, we have

$\phi(i, j, k, t)=\frac{e^{-\lambda t}(\lambda t)^{i-s_{2}-1}}{\left(i-s_{2}-1\right) !} \mathcal{C} \phi\left(s_{2}, j, k-1+s_{2}, t\right) ; \quad s_{2}+1 \leq i \leq S_{2} ; \quad 0 \leq j \leq S_{2} ;$

For $i+1 \leq k \leq S_{1}$, we have

$\phi(i, j, \quad k, \quad t)=\mu e^{-\mu t} \sum_{\ell=0}^{i 1} \frac{e^{-\lambda t}(\lambda t)^{\ell}}{\ell !}$ C $\phi\left(i-1+S_{2}-S_{2}, j, k-\ell, t\right)+$ $\mu e^{-\mu t}\left[1-\sum_{\ell=0}^{i-1} \frac{e^{-\lambda t}(\lambda t)^{\ell}}{\ell !} \subset \phi\left(S_{2}-s_{2}, j k-\ell, t\right)\right] ; \quad 1 \leq i \leq s_{2} ; \quad 0 \leq j \leq S_{2} ;$

$\phi(i, j, k, t)=\frac{e^{-\lambda t}(\lambda t)^{i-s_{2}-1}}{\left(i-s_{2}-1\right) !}\left(\mathcal{C} \phi\left(s_{2}, j, k-i+s_{2}, t\right), \quad s_{2}+1 \leq i \leq S_{2} ; \quad 0 \leq j \leq S_{2}\right.$ 


\section{INVENTORY LEVEL DISTRIBUTION}

Let $0=\mathrm{T}_{0} ; \mathrm{T}_{1} ; \mathrm{T}_{2} ; \ldots$ be the time points at which reorders for product 1 are placed, and let $\mathrm{X}_{\mathrm{n}}$ $=\mathrm{L}_{2}\left(\mathrm{~T}_{\mathrm{n}}+\right)$. Then, we observe that the process

$$
(X, T)=\left\{\left(X_{n}, T_{n}\right) ; n=0,1,2, \ldots\right\}
$$

is a MRP with a state space

$$
E=\left\{0,1,2, \ldots, s_{2}, \ldots, S_{2}-1\right\}
$$

The semi-Markov kernel (see Cinlar, 1975) of this process is the family of probabilities defined by

$$
Q(i, j, t)=P\left[X_{n+1}=j, T_{n+1}-T_{n}<t / X_{n}=i\right] \text { where i, } j \in E
$$

To derive an expression for $Q(i, j, t)$, we consider the following mutually exclusive and exhaustive possibilities:

(i) Replenishment for product 1 occurs when the inventory level of product 1 is not zero.

(ii) Replenishment for product 1 occurs when the inventory level of product 1 is zero.

Accordingly, we have

$$
\begin{aligned}
& Q(i, j, t)=\int_{0}^{t}\left[\sum_{j^{\prime}=0}^{S_{2}} \sum_{\ell=0}^{s_{1}-1}\left\{g(u) \phi\left(i, j^{\prime}, \ell, u\right)\right\} \Subset \phi\left(j^{\prime}, j+1, S_{1}-\ell-s_{1}-1, u\right) \lambda\right. \\
& \left.+\sum_{j^{\prime}=1}^{S_{2}}\left\{g(u) \int_{0}^{u} \phi\left(i, j^{\prime}, s_{1}-1 v\right) \lambda d v\right\} \Subset \phi\left(j^{\prime}-1, j+1, S_{1}-2 s_{1}-1, u\right) \lambda\right] d u
\end{aligned}
$$

We now define a Markov renewal function of $(X, T)$ as

$$
R(i, j, t)=\sum_{n=0}^{\infty} \phi(i, j, t) ; i, j \in E
$$

The Markov renewal kernel of the $(X, T)$ is the matrix $\boldsymbol{R}(t)=[R(i, j, t)]$. Setting $\boldsymbol{Q}(t)$ as the $\left(S_{2}+1\right) X\left(S_{2}+1\right)$ order matrix $[Q(i, j, t)]$, we obtain from the theory of Markov renewal processes.

$$
\boldsymbol{R}^{*}(s)=\left[I-\boldsymbol{Q}^{*}(s)\right]^{-1}
$$

Now to determine the distribution of two-product inventory levels, we consider the vector process

$$
Z(t)=\left(L_{1}(t), L_{2}(t)\right) ; \quad t \geq 0 .
$$


This process is clearly a semi-regenerative process on the state space

$$
F=(i, j): \begin{aligned}
& \left\{i=0,1,2, \ldots, S_{1}, \ldots, S_{1}\right. \\
& \left.j=0,1,2, \ldots, S_{2}, \ldots, S_{2}\right\}
\end{aligned}
$$

It is evident that the MRP $(X, T)$ is embedded in $Z(t)$ (see Cinlar, 1975). We define for any (i,j) $\in F$

$$
\left.P\left(i, j, t \mid s_{1}, j_{0}\right)=P|Z(t)=(i, j)| E_{0}\right\rfloor
$$

The function $P\left(i, j, t \mid s_{1}, j_{0}\right)$ gives the two-product inventory level distribution at any time $t$, and to derive the expression for it, we consider the function on $k\left(i, j, t \mid s_{1}, j_{0}\right)$ defined by

$$
K\left(i, j,\left.t\right|_{s_{1}}, j_{0}\right)=P\left[Z(t)=(i, j) ; T_{1}>t \mid E_{0}\right]
$$

We observe that $K\left(i, j, t \mid s_{1}, j_{0}\right)$ gives the probability that given a reorder is made at time $T_{0}$ and that the inventory level then is $\left(s_{1}, j_{0}\right)$, the subsequent reorder is placed only after time $t$ and the inventory level at time $t$ is $(i, j)$. To derive $K\left(i, j, t \mid s_{1}, j_{0}\right)$ we have the following cases:

Case 1: $i \leq s_{1}$

In this case, we observe that no replenishment for product 1 can occur in $(0, t)$ and exactly $\left(s_{1}-i\right)$ demands are satisfied in $(0, t)$. Hence, we have

$$
K\left(i, j, t \mid s_{1}, j_{0}\right)=\bar{G}(t) \phi\left(j_{0}, j, s_{1}-i, t\right)
$$

Case 2: $i>S_{1}-s_{1}$

Here we note that a replenishment for product 1 should occur before $t$ and only $0 \leq \ell \leq S_{1}-i$ demands can be satisfied as the inventory level of product 1 after replenishment should be above $i$. Hence we have

$$
K\left(i, j, t \mid S_{1}, j_{0}\right)=\sum_{j^{\prime}=0}^{S_{2}} \sum_{\ell=0}^{S_{1}-i} g(t) \phi\left(j_{0}, j^{\prime}, \ell, t\right) \odot \phi\left(j^{\prime}, j, S_{1}-\ell-i, t\right)
$$

Case 3: $s_{1}<i<S_{1}-s_{1}$

In this case, a replenishment for product 1 occurs before $t$ and it occurs either before or after the inventory level of product 1 becomes zero. Hence

$$
\begin{aligned}
& K\left(i, j, t \mid s_{1}, j_{0}\right)=\sum_{j^{\prime}=0}^{S_{2}} \sum_{\ell=0}^{s_{1}-1} g(t) \phi\left(j_{0}, j^{\prime}, \ell, t\right) \Subset \phi\left(j^{\prime}, j, S_{1}-\ell-i, t\right) \\
& +\sum_{j^{\prime}=1}^{S_{2}}\left\{g(t) \int_{0}^{t} \phi\left(j_{0}, j^{\prime}, s_{1}-1, u\right) d u\right\} \Subset \phi\left(j^{\prime}-1, j, S_{1}-s_{1}-i, t\right)
\end{aligned}
$$


Now to obtain an expression for $P\left(i, j, t \mid s_{1}, j_{0}\right)$, we condition on $T_{1}$ and use the regenerative property of $Z(t)$. Accordingly, we get

$$
P\left(i, j, t \mid s_{1}, j_{0}\right) t=K\left(i, j, t \mid s_{1}, j_{0}\right)+\sum_{j^{\prime}=0}^{S_{2}} \int_{0}^{t} Q\left(j_{0}, j^{\prime}, d u\right) P\left(i, j, t-u \mid s_{1}, j^{\prime}\right)
$$

From the theory of MRP, we obtain

$$
P\left(i, j, t \mid s_{1}, j_{0}\right) \int_{0}^{t} R\left(i, j, d u \mid j_{0}, j^{\prime}\right) K\left(i, j, t-u \mid s_{1}, j\right)
$$

the distribution of inventory level of the system, at any time $t$.

\section{LIMITING DISTRIBUTION OF THE INVENTORY LEVEL}

Let $\Pi=\left(\Pi_{1}, \Pi_{2}, \ldots, \Pi_{S_{2}}\right)$ be the stationary distribution of a Markov chain $Z_{n}$. Then $\Pi$ is the solution of the equation $\Pi \overline{\mathrm{Q}}=\Pi$ where $\overline{\mathrm{Q}}$ is the $\left(S_{2}+1\right) X\left(S_{2}+1\right)$ order matrix with its elements given by

$$
\bar{Q}(i, j)=\lim _{t \rightarrow \infty} Q(i, j, t)
$$

Let $m(i)=E\left[T_{n+1}-T_{n} \mid Z_{n}=i\right]$ be the mean sojourn time in the state $i$ of the MRP $(Z, T)$. Then, we have

$$
m(i)=\int_{0}^{\infty}\left[1-\sum_{i, j \in E} Q(i, j, t)\right] d t
$$

Hence applying a theorem of semi-regenerative processes, we get

$$
\lim _{t \rightarrow \infty} P\left(i, j, t \mid s_{1}, j_{0}\right)=P(i, j)=\sum_{k \in E} \frac{\Pi(k) \int_{0}^{\infty} K\left(i, j, t \mid s_{1}, k\right) d t}{\Pi m}
$$

where $m=\left[m(1), m(2), \ldots, m\left(S_{2}\right)\right]$.

\section{MEASURES OF SYSTEM PERFORMANCE}

In this section, we proceed to obtain certain measures of performance of the system.

\subsection{Mean number of lost demands}

The first-order product density of the lost demands is given by 


$$
h_{j_{0}}^{\ell}(t)=\sum_{i=0}^{S_{1}} P\left(i, 0, t \mid s_{1}, j_{0}\right) \lambda+\sum_{j=1}^{S_{2}} P\left(0, j, t \mid s_{1}, j_{0}\right) \lambda
$$

So the mean number of demands lost in the interval $(0, \mathrm{t}]$ is $\int_{0}^{t} h_{j_{0}}^{\ell}(u) d u$. Hence the stationary mean rate of demands lost is given by

$$
E(\ell)=\sum_{i=0}^{S_{1}} P(i, 0) \lambda+\sum_{j=1}^{S_{2}} P(0, j) \lambda
$$

\subsection{Mean number of reorders}

The first order product densities of $R_{i}, i=1,2$ events are given by

$$
\begin{aligned}
& h_{j_{0}}^{R_{1}}(t)=\sum_{j=1}^{S_{2}} P\left(s_{1}+1, j, t \mid s_{1}, j_{0}\right) \lambda . \\
& h_{j_{0}}^{R_{2}}(t)=\sum_{i=1}^{S_{1}} P\left(i, s_{2}+1, t \mid s_{1}, j_{0}\right) \lambda .
\end{aligned}
$$

and the respective stationary mean rates of $R_{1}$ and $R_{2}$ are

$$
\begin{aligned}
& E\left(R_{1}\right)=\sum_{j=1}^{S_{2}} P\left(s_{1}+1, j\right) \lambda . \\
& E\left(R_{2}\right)=\sum_{i=1}^{S_{1}} P\left(i, s_{2}+1\right) \lambda .
\end{aligned}
$$

\subsection{Mean number of demands satisfied}

The first-order product density of the process of $d$-events is

$$
h_{j_{0}}^{d}(t)=\sum_{\ell=1}^{S_{1}} \sum_{j=1}^{S_{2}} P\left(i, j, t \mid s_{0}, j_{0}\right) \lambda .
$$

and the mean stationary rate of the demands satisfied is

$$
E(d)=\lambda \sum_{i=1}^{S_{1}} \sum_{j=1}^{S_{2}} P(i, j) .
$$

\subsection{Cost analysis}

We note that $P(i, j)$ is the fraction of time the process $Z(t)$ spends in $(i, j)$. The expected holding cost per unit time is $\left(c_{1} i+c_{2} j\right) P(i, j)$. The total expected cost per unit time is 


$$
C\left(S_{1}, S_{2}, s_{1}, s_{2}\right)=\sum_{i=0}^{S_{1}} \sum_{j=0}^{S_{2}}\left(c_{1} i+c_{2} j\right) P(i, j)+E(\ell) C_{2}+\sum_{i=1}^{S_{2}} E\left(R_{i}\right) c_{R i} c_{q_{i}}
$$

where $c_{R_{i}}$ is the reordering cost product $i$ and $c_{q_{i}}$ is the buying price of product $i$. Therefore $P R O F I T=E(d) c_{t_{i}}-C\left(S_{1}, S_{2}, s_{1}, s_{2}\right)$.

\section{NUMERICAL ILLUSTRATION}

For the purpose of illustration, we assume

$$
g(t)=\frac{a b}{b-a}\left[e^{-a t}-e^{-b t}\right] ; a>0, b>0
$$

$a=0.1 ; \quad b=0.01 ; \quad S_{1}=6 ; \quad s_{1}=2 ; \quad S_{2}=4 ; \quad s_{2}=1 ; \quad \lambda=0.5 \quad$ and $\mu=0.5$

We compute the measures of performance of the system by ranging $\lambda$ from 0.5 to 5.5 and obtain table 1. In this table, we observe that as the mean demand rate increases, the mean stationary rate of reorders for both the products and that of demands lost and satisfied also increases. In table 2, we present the stationary rates of cost and the profit for various values of reorder levels of the two products. We note that the optimum value corresponds to $s_{1}=2$, $s_{2}=1$.

\begin{tabular}{ccccc}
\hline$\lambda$ & LOST & REORD 1 & REORD 2 & SATIS \\
\hline 0.5000 & 0.1332 & 0.0807 & 0.1198 & 0.3594 \\
1.0000 & 0.3336 & 0.1266 & 0.2158 & 0.6474 \\
1.5000 & 0.5612 & 0.1553 & 0.3010 & 0.9030 \\
2.0000 & 0.8091 & 0.1751 & 0.3811 & 1.1434 \\
2.5000 & 1.0674 & 0.1895 & 0.4585 & 1.3756 \\
3.0000 & 1.3321 & 0.2006 & 0.5343 & 1.6028 \\
3.5000 & 1.6013 & 0.2093 & 0.6090 & 1.8270 \\
4.0000 & 1.736 & 0.2164 & 0.6830 & 2.0490 \\
4.5000 & 2.1483 & 0.2223 & 0.7565 & 2.2695 \\
5.0000 & 2.4247 & 0.2272 & 0.8296 & 2.4889 \\
5.5000 & 2.7025 & 0.2315 & 0.9025 & 2.7074 \\
\hline
\end{tabular}

Table 1: Increasing demand rate

\begin{tabular}{cccc}
\hline $\mathrm{s}_{1}$ & $\mathrm{~S}_{2}$ & PROFIT & COST \\
\hline 2 & 1 & 326.6472 & 503.5375 \\
2 & 2 & 365.9118 & 481.5439 \\
2 & 3 & 413.3092 & 444.3516 \\
3 & 2 & 372.3246 & 457.5576 \\
3 & 3 & 421.8203 & 417.3643 \\
4 & 1 & 352.0535 & 439.0807 \\
4 & 2 & 400.3319 & 412.2556 \\
4 & 3 & 434.8828 & 381.9120 \\
\hline
\end{tabular}

Table 2: Optimal reorder level 


\section{REFERENCES}

[1] Schmidt, C.P. \& Nahmias. (1985). Optimal policy for a two-stage assembly system under random demand. Operations Research, Vol. 35, pp 1130-1145.

[2] Yano, C.A. (1987). Stochastic lead-times in two-level assembly systems. IIE Transactions, Vol. 19, pp 371-378.

[3] Fujiwara, O. \& Sedarage, D. (1997). An optimal (Q, r) policy for a multipart assembly system under stochastic part procurement lead times. European Journal of Operations Research, Vol. 100, pp 550-556. 